\title{
OPTIMISATION OF MANAGEMENT ACTIVITY IN SPORTS ORGANIZATIONS
}

\author{
Florentin VASILESCU ${ }^{1 *}$, Corina ȚIFREA ${ }^{1}$ \\ ${ }^{1}$ National University of Physical Education and Sport, Faculty of Physical Education and Sport, \\ Bucharest, Romania \\ *Corresponding author: vasilescuiulian81@yahoo.com
}

https://doi.org/10.35189/dpeskj.2020.59.s.8

\begin{abstract}
Sport management is part of a complex area that involves all the aspects of sports business. The management process has a universal character, being developed and taking place in the internal but also the external environment of organizations, in stages that involve: diagnosis of situations, planning and decisionmaking, organization, coordination of resources, control and evaluation of the results. In the sporting activity, managers organize the execution work in order to obtain increased efficiency, taking into account the needs and aspirations of people, as well as the importance of the unit and activities they lead. This management involves a high number of abilities and directions, out of which many are connected to the strategies, statistics, and the usage of the technology information, accountancy and communication. All of this is ultimately leading to the achievement of sports results. Regardless of the sports branch, the achievements are desired at all levels, starting from the members of the family to the administrator, from the director to the governmental bodies, giving purpose, satisfaction and generating the sports policy. One of the objectives was to improve the activities of sports organizations in communication management, public relations management, human resource management and evaluation management. This paper aimed at selecting effective methods, as well as developing a management analysis model following the research conducted in order to optimise and develop the management of sports organizations.
\end{abstract}

Keywords: optimisation, management, sports organizations.

\section{Introduction}

The globalisation and adoption of a market economy have made more and more the innovation to be fundamental to the success of professional sports organizations. However, oligarchic league structures, isomorphic and hyper-traditional cultures and hierarchical organizational structures can enhance or hinder organizational creativity, the beginning stage of the innovation process. (Smith \& Green, 2020)

By its nature and the stake it represents, the sport must develop a coherent global strategy finalised by a report of the different purposes as well as by products that can promote it in a specific way in order to achieve its goals and maintain autonomy.

The management process has a universal character, being developed and carried out in the internal but also the external environment of organizations, in stages that involve: diagnosis of situations, planning and decision-making, organization, coordination of resources, control and evaluation of the results. In the sporting activity, managers organize the executive work in order to obtain increased efficiency, taking into account the needs and aspirations of people, as well as the importance of the unit and activities they lead. Management involves a large number of skills and orientations, many of which are related to strategies, statistics, the use of information technology, accounting and communication. The sports activities carried 
out by the profile organizations require a more in-depth investigation that would allow to know the complex mechanisms of management and identify solutions for financial optimisation, human resources, selection and preparation for large-scale competitions. All these steps ultimately lead to sports performance.

\section{Particularities of sports management}

Due to the social evolution, it was necessary to apply managerial concepts in sports in a systematic integrative vision through the unitary approach to the components of organizational activity, forms, ideas, tools, attitudes etc. taken over from countries with extensive experience in this field, and this real incursion of information and forms of managerial intervention was decisively influenced by the absence, until 1990, of the formal aspect of an institutional framework addressing management issues. Starting from the allegation that management has become the universal organ that is spreading everywhere in modern society (Gavrilă \& Lefter, 2002), several authors have defined sports management as: 1. the resource-centred vision according to which management means the coordination of human, informational, material and financial resources in order to achieve the purpose of the organization (Colibaba-Evuleț \& Bota, 1998); 2. the vision that takes into account the process according to which sports management means all the specific processes and relationships through which the resources of a sport structure are organized, administered and managed both as a whole and by level and component in order to achieve the proposed effective objectives (Mihăilescu, 2006).

Sports management ensures the continuous and permanent management of sports activities by determining effectiveness and control over the systems and situations involved (Endres \& Kleiner, 1990).

Management in sports is a catalyst for both the sports structures and their specific activities because it contributes to achieving efficiency by detecting, encouraging and stimulating people with special skills for sports through the selection process, ensuring a psycho-social climate that encourages and rewards those who continually do their best to achieve superior performance (Lussier \& Kimball, 2009). The substantial contribution offered by the sports management in determining and training the sports activities, as well as in the selection and promotion of the competent personnel, determines optimal conditions for carrying out productive and efficient activities within the sports organizations.

Both employment and dismissal are largely determined by gross performance and, to a lesser extent, relative performance (Salaga \& Juravich, 2019).

For the sports industry to develop, it is necessary to have a continuous flow of qualified specialists who can adapt and apply the strategies of progress in this field. The activities of those who now profess in the field of management in sports organizations, being anchored in the present indigenous reality, are in fact the ones that will direct and organize the training course of future specialists. The experience of the current sports managers makes them responsible for structuring, evaluating and self-evaluating the possibilities to choose and act, which are the achievements and concerns that will lead to the success of their institutions but also to the great performance of athletes. (Zhang et al., 2018) 


\section{Abilities and competencies of the sports manager}

Motivation. It is a significant element in the management of any sports organization, generating success especially in the transition phases. To have a progressive development, there is a need for leadership to understand and permanently improve employee motivation.

Motivation is another significant outcome of leadership. There is an old saying that 'you can take a horse to the water but you cannot force it to drink, it will drink only if it's thirsty' and same is the case of the workforce in the organization. They will perform as they want to perform or motivated to perform. Employee motivation is considered the main factor for any organization to perform well, especially in the transition phases. To better cope with these challenges, there is a growing need for leadership to understand and improve employee motivation. Employee motivation is a key function of any leadership position. In order to survive and succeed in the global world, a leader must know how to motivate employees. Motivation means to use or develop such a strength in a person that causes that person to behave in a directed way. (Asrar-Haq \& Anwar, 2018)

Following the transformational leadership style, managers can approach different motivational strategies that lead to higher return of those involved such as: collaboration with employees in decision-making, certification of employees, job rotation, changing the communication mode. Motivation for work is characterised by a series of motivational factors, which are both intrinsic (needs, attitudes, interests, perception of tasks, value systems) and extrinsic (salary, task assignment, control systems, communication, workgroup) and will determine the individual's motivated or unmotivated behaviour.

Communication skills. Communication provides the sports manager with optimal means of interaction for fulfilling their roles and objectives. Communication skills help managers to carry out their activity efficiently, but also to make the right decision to reach the proposed goal. Information transmission and receiving responses is essential within organizations for awareness and understanding of the objectives but also for the external promotion of their image. Mutual interaction through communication is based on feedback, after verifying if the decisions transmitted by the subordinate manager have been consciously perceived. For a group to synergistically correlate their efforts, communication must influence and change the perceptions, behaviours, attitudes and feelings of the recipients. The manager perceives communication as a tool that management uses to exercise its specific tasks: organization, training, control and evaluation, while helping to change mentalities.

Setting priorities. Efficient priority-based management will always shorten the time until the objectives are reached. The manager identifies and sets the priorities to be followed, which reflect the strategic agenda of the organization. Clear priorities help employees channel their attention, energy and resources. Managers can set their priorities according to four criteria: 1. What is important, 2. What is urgent, 3. Which ones are in are short term, 4. Which ones are in the long term. To achieve the goals, all members of the group must accept and understand the priorities set by the manager.

Setting the objectives. In establishing the operational objectives, it is essential for all departments of the organization as well as the executive staff to collaborate so that there are no divergences related to goal acceptance. Initial leadership efforts to shape employee attitudes that are not sustained may be wasted (Henricks et al., 2020). The manager's 
responsibility is to correlate the operational objectives with the organizational objectives and to ensure that they will motivate the subordinate without appearing unattainable. The setting of objectives must take into account a series of rules that will facilitate their achievement:

- Be precise and measurable

- Have a deadline to meet

- Be clear, unambiguous

- Be sorted according to priorities

- Be a challenge but not unachievable

- Be in accordance with the organization's policies

- Be oriented towards the result

Time management. Time is an essential resource for management, determining to a large extent technical and economic progress. Although it is inelastic and perishable, unlimited but irreplaceable, its loss cannot be "compensated". Time management involves scheduling, anticipating and responding to actions in a planned and efficient manner, offering concrete advantages such as: setting priorities, delegating tasks, achieving goals, better communicating, developing creativity, achieving more results in a unit of time, easily adapting to change, maintaining a balance between professional life and personal life.

Strategic planning is a production process. The outcome of the planning process is a plan. A plan is a formulated method and a detailed method by which something must be done. The plan that results from the planning process details the interventions to be implemented, the objectives pursued and some of the objectives that must be reached to meet the identified needs. It also defines the priorities, sequencing and timing over which each of the goals has to be met (Strategic planning, 2014). Many managers who are not aware of their personal tendency to use time inefficiently may, for example, perform unplanned activities before the scheduled ones, making it possible for the important activities to remain unresolved.

Evaluation. The need for quantifying human capital emerged naturally with its use in economic research, but so did problems of measurement (Ion, 2011). Evaluation provides managers with analytical information about employee performance. The concept of evaluation consists in determining the ability of an individual or group (department, team) to positively complete the tasks, responsibilities and challenges imposed by each one's position and role in the organization. Basic conditions need to be established for effective evaluation:

- Evaluation should not be a way of controlling staff.

- Evaluation should increase employee cooperation and motivation.

- Evaluation should aim to achieve the objectives.

- Evaluation should identify the needs and offer solutions for their management.

In the process of staff evaluation, there are risks that managers need to take into account:

- Evaluation should be perceived by employees as a useful process rather than a formal bureaucratic procedure.

- Evaluation should not be done according to the individual but according to performance.

- Evaluation should be constructive and focused on professional and organizational development.

Evaluation can include aspects such as: objectives achieved, perceived efficiency of the evaluated individual, impediments observed in the evaluation process, identified needs and ways to improve them. 


\section{Purpose of study}

This paper aims at the complex combination of information and findings regarding sports organizations as well as the selection of methods and tools that can lead to the optimisation of managerial activities.

\section{Objectives of study}

- Developing the activity of sports organizations in communication management, public relations management, human resources management and evaluation management, considering the characteristics of planning, organizing and controlling the processes involved.

- Increasing the efficiency of the decision-making component regarding the performance and functionality of sports organizations.

- Noting the importance and role of the personality components of the sports manager.

- Writing a relevant scientific analysis questionnaire according to the researched theme.

- Detecting viable and realistic solutions for efficient management in the activity of sports organizations.

By determining interventions on human and organizational resources, a strategy for increasing managerial efficiency can be developed, which implies a solid support of the knowledge in the field, experience and skills of the people with delegated competencies for this purpose.

\section{Assumptions}

- The particularities of performance sports and sports management in sports organizations differ depending on the management styles, complexity of the processes and characteristics of sports activities.

- The particularities of performance sports and sports management in sports organizations differ depending on the human resources and material accessed.

- The efficiency of managerial activities can increase considerably if managers pay constant attention to the optimisation of managerial processes specific to sports organizations.

- The transformational management style is positively associated with the managerial performance of the leaders of sports organizations.

\section{Methodology}

In our approach, we applied an appropriate range of methods, starting with the study of the literature and continuing with a sociological survey using two questionnaires for the managers of sports organizations. The object of the investigation consisted in selecting from reality some pertinent elements of the studied behaviours and social factors.

The research was conducted on 40 managers from 14 regions of the country and Bucharest. The most numerous managers are from the capital, Constanța, Brașov and Cluj; at the opposite pole, there are the regions with a single representative: Alba, Botoşani, Maramureș, Dolj, Galați and Teleorman. 
The structure of the sample in relation to the sports positions of the investigated subjects is shown in Table 1.

Table 1. Structure of the sample in relation to the sports positions performed by subjects

\begin{tabular}{lcc}
\hline \multicolumn{1}{c}{ Position } & Situations & Percentage $(\%)$ \\
\hline Coach manager & 4 & 10.3 \\
Director & 6 & 12.8 \\
Executive director & 13 & 33.3 \\
Technical director & 1 & 2.6 \\
Coordinator director & 1 & 2.6 \\
Sporting director & 5 & 12.8 \\
Chairman manager & 1 & 2.6 \\
Chairman & 1 & 2.6 \\
Manager & 8 & 20.5 \\
Total & 40 & 100 \\
\hline
\end{tabular}

Most of the sports managers participating in our study are college and Master's graduates, some of them even holding the title of $\mathrm{PhD}$ (Figure 1).

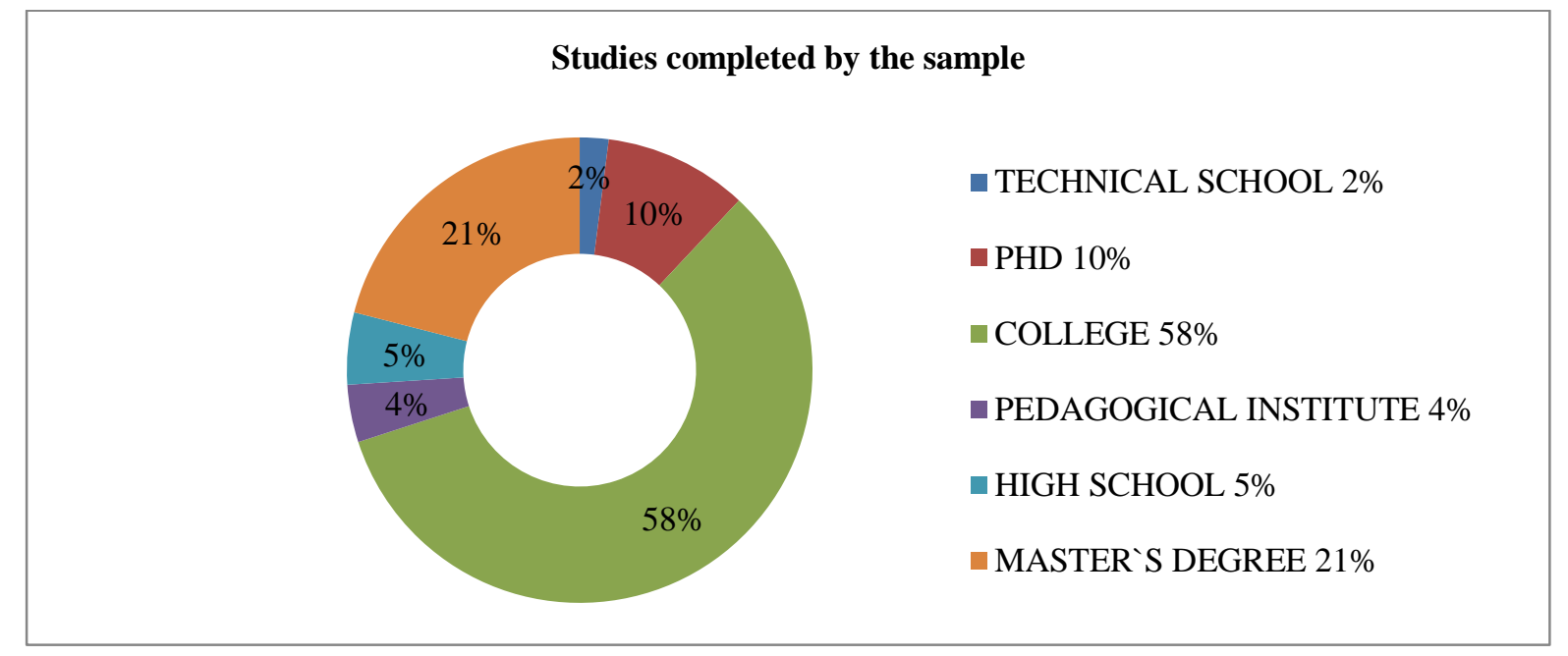

Figure 1. Diagram according to the studies completed by the investigated subjects

Managerial ability is a multidisciplinary competence, the profession of manager assuming a set of skills, knowledge and techniques that exceed the initial specialised ones and aim at the organization of activities, the strength and ability to establish modern information flow in order to make the best use of human and material resources through correct decisions.

Most of the study participants consider managerial training to be very important in sports success and only $6 \%$ of them think it is appropriate. None of them thinks that this criterion is irrelevant (Figure 2). 


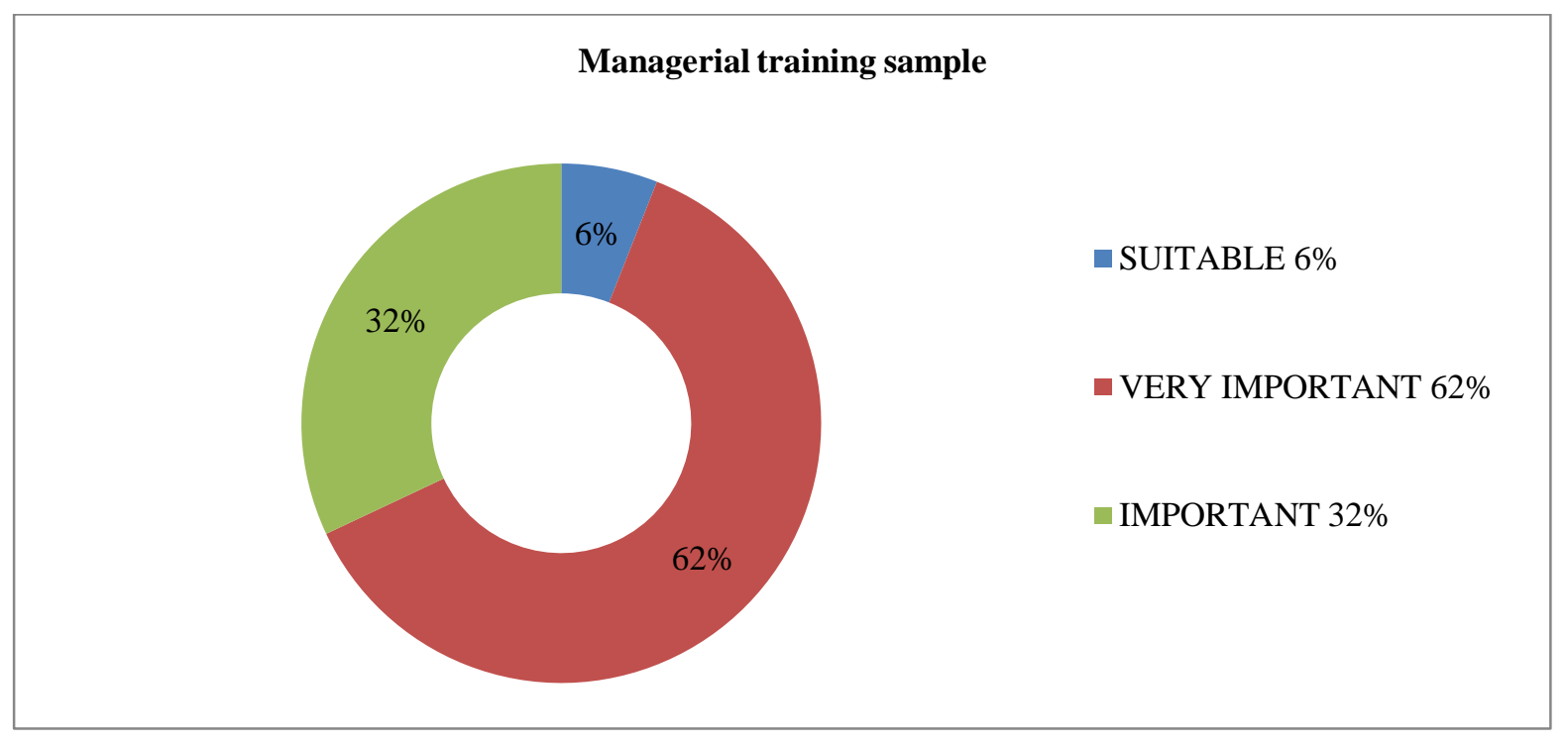

Figure 2. Diagram of the values according to the role of managerial training for the investigated subjects

After establishing the sample, we identified the type of information corresponding to the objective of our research. The subjects received two questionnaires: one specialised in the field of sports management with 20 items to prove both quantitatively and qualitatively different aspects such as: factors of success in sport, the role of facilities and financial resources, crisis management and time management in sports organizations, systematisation of athletic performance in competitions of different levels. The second one was the Multifactor Leadership Questionnaire with 45 items and 12 distinct scales: 1.IA Inspire confidence - 4 items, 2.IB Act with confidence - 4 items, 3.IM Inspire those involved - 4 items, 4.IS Stimulate creative thinking - 4 items, 5.IC Develop those involved - 4 items, 6.CR Gratify the results - 4 items, 7.MBEA Follow the mistakes - 4 items, 8.MBEP Fight the problems - 4 items, 9.LF Avoid involving - 4 items, 10.EE Determine the level of effort - 3 items, 11.EFF Fear to perform well - 4 items, 12. Connect - generate satisfaction - 2 items.

The Multifactorial Leadership Questionnaire (MLQ) is a complex tool developed to provide a clear dimension of the transformational, transactional and passive/avoidance components of leadership, as well as a more complete profile of a candidate's performance and potential for leadership. MLQ is one of the most commonly used leadership tools in field and laboratory research, being appropriate and very useful in the activities of selection, transfer, promotion, development and individual, group or organizational counselling. (Antonakis et al., 2003)

MLQ scales can help measure the impact of different types of leaders on their colleagues, the teams they lead and the effectiveness of organizations in which they operate. We can thus quantify the area of influence of the leadership model of managers in different fields (business, industry, military, educational, religious, administrative, governmental, sports) and see to what extent this model affects the satisfaction of subordinates and colleagues, team efficiency and organizational success. (Iliescu et al., 2008) 
The first 5 scales assess transformational leadership, scales 6 and 7 assess transactional leadership, scales 8 and 9 measure passive leadership, and the last scales, 10, 11 and 12, assess leadership outcomes. The fundamental characteristics of sports management, with an effect on the performance of sports associates, are the motivation of athletes, attracting sponsors and the transfer of valuable athletes, but also the delegation of tasks (Figure 3).

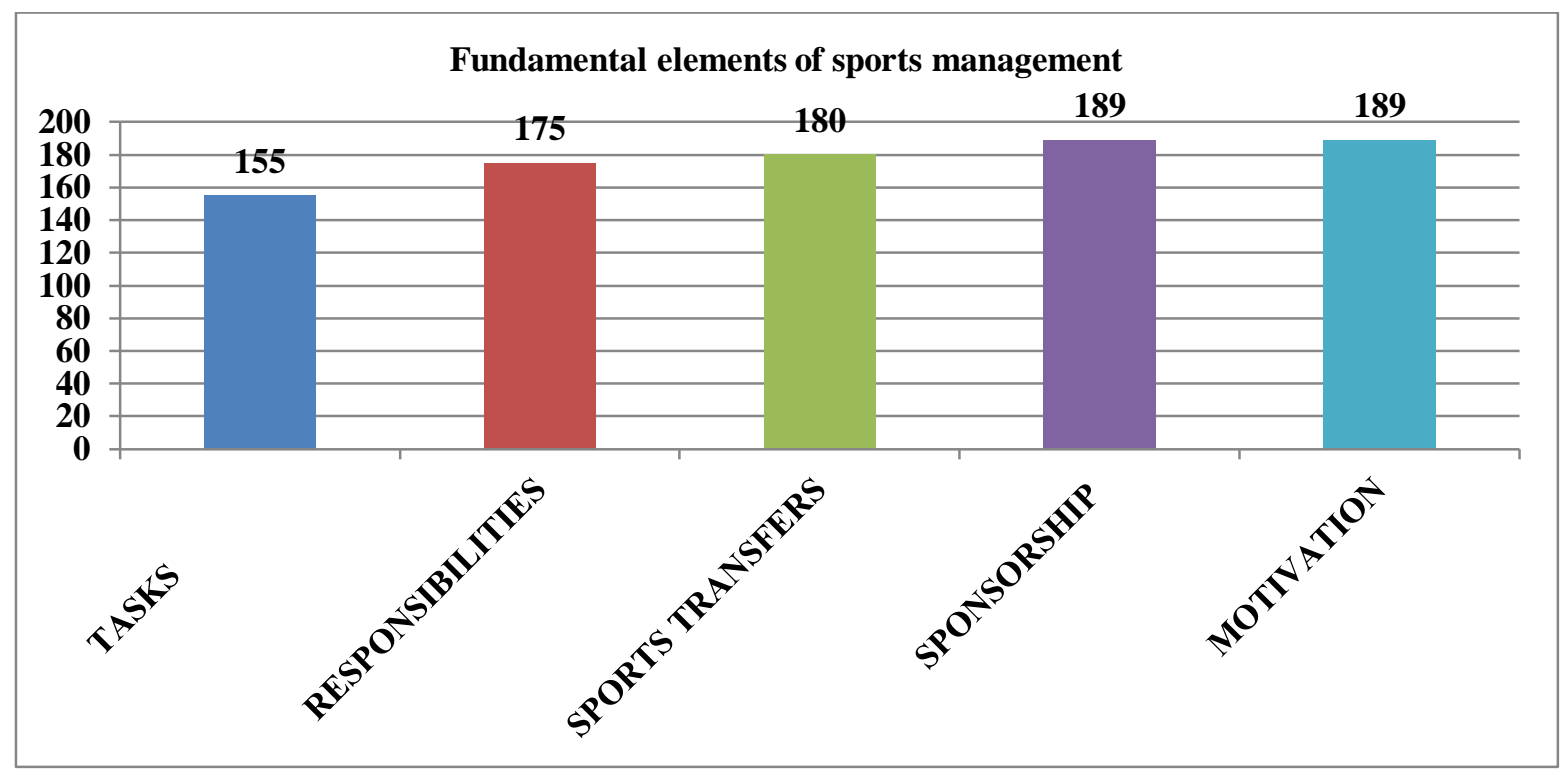

Figure 3. Diagram of the total results of some fundamental elements in the management of sports organizations

In the opinion of managers participating in the study regarding the importance of their skills and competencies, the first places come to the motivation of athletes and staff, followed by the communication skills and finally the time management ones (Figure 4).

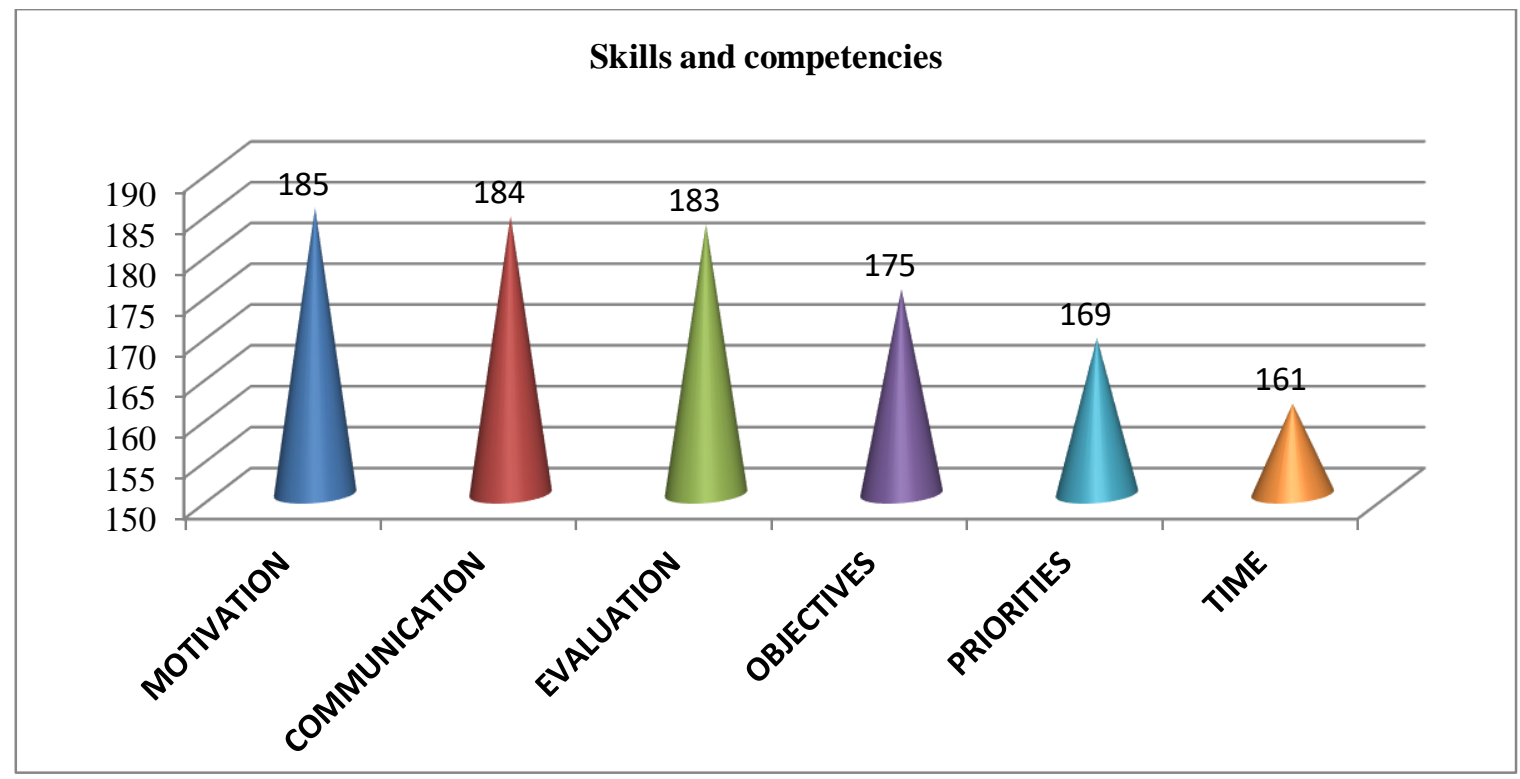

Figure 4. Skills and competencies of sports managers 
Regarding the factors that influence the results in competitions, it was surprising to find the material ones in the last places in managers' choices, and the human ones, such as the value of athletes and the competence of those who lead the training processes (teachers, coaches, trainers), to be considered the most important (Figure 5).

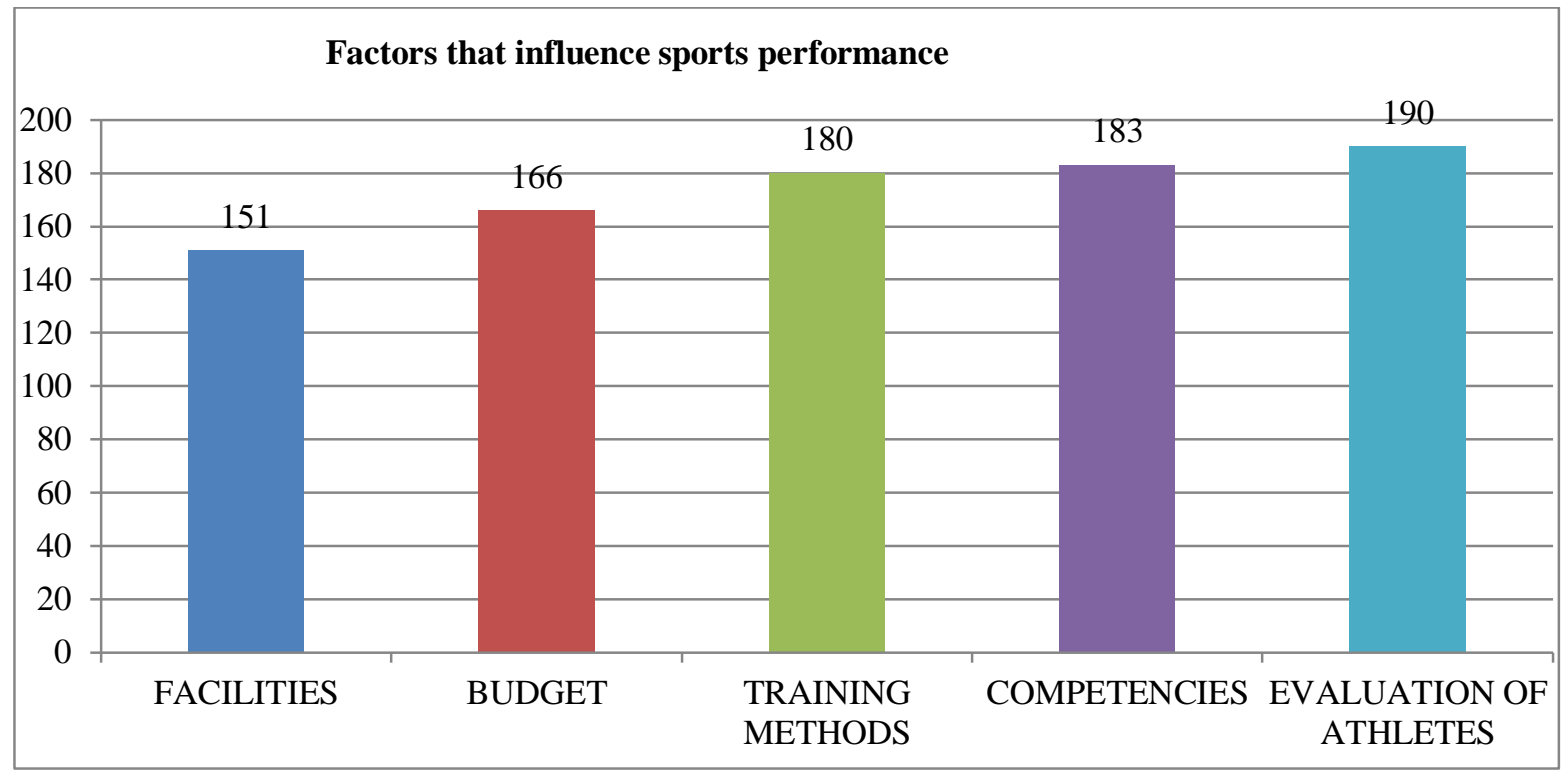

Figure 5. Comparison of total results in evaluating the importance of factors that influence the performance of athletes in competitions

The motivational paths preferred by the investigated managers were the positive verbal appreciations and salary remuneration with bonuses, while the distinctions and diplomas are in the last place (Figure 6).

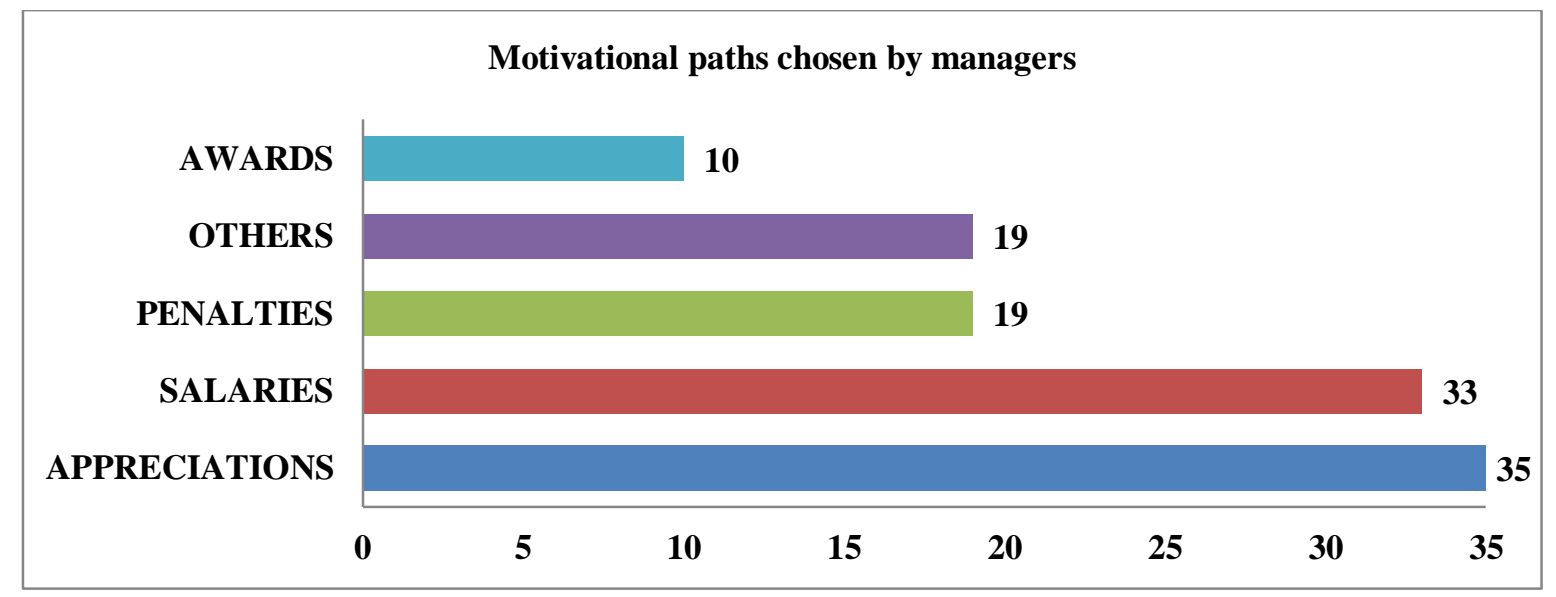

Figure 6. Motivational paths chosen by the investigated sports managers 


\section{Results}

- Based on the study of the literature, we were able to analyse and define the specific concepts of sports organizations in order to develop a contextual framework according to empirical research.

- Sports management strategies, policies and practices that contribute to the achievement of objectives have led to the formation of a management analysis model in sports organizations involved in the research.

- Establishing ways in which the design and satisfaction of fans can contribute to performance by developing effective strategies and policies.

- The research determined a relative stage of design, operationalisation and organization of activities and processes, policies and strategies implemented in order to ensure a competitive privilege.

- Regulating a model for evaluating and rewarding the activity of employees in all departments of sports organizations.

- The characteristics and variables of the processes of organization, coordination, planning, training motivation and control that determine the efficiency of management actions and strategies were identified.

It should be noted that the research results provide the premises for a rigorous analysis of the issues highlighted.

\section{Conclusion}

At the end of our research, after correlating all the data and information, we could draw the following conclusions:

- The evolution of the sporting phenomenon in the last decades has represented its transformation into a complex industry capable of mobilising human, financial and material resources with impact effects on social and economic life.

- It is urgently necessary to develop a managerial strategy in all sports organizations to raise awareness and the consequent application of theories, techniques, styles and managerial methods to ensure success.

- Awareness of the importance of human resources must be a priority for sports managers, generating substantial profits with direct links to productivity and performance.

- In sports organizations, systematic and continuous appraisals and evaluations of the staff performance in relation with the established objectives must be made.

- The special interest of handlers in transferring some valuable athletes is noted, which highlights the importance of financial resources that play a vital role in the assiduity and viability of sports organizations.

- The considerable revenues from sports organizations are primarily generated by sponsorships and donations as opposed to the initiation of sports and sports demonstrations that bring the least money into the sports club's budget.

- In order to attract sponsors and supporters to support athletes, it is necessary to establish partnerships with media sources. 
- Senior managers in organizations consider that a special role in motivating athletes is played by the corresponding remuneration for them, while young managers are less materialistic and more idealistic.

- Professional experience and studies make a positive impression on managerial styles.

- After investigating the interference of the quantitative variables of the research, a positive relation was observed between the elements of transformational management and the managerial competencies of surveyed subjects.

- In-depth study managers have adopted a style based on the development of the team they work with, which corresponds to the transformational one, giving up absolute control and developing superior managerial skills.

- According to the results of the MLQ-45 questionnaire, the only managerial style that correlated negatively with the other styles and proved to be counterproductive was the one based on non-involvement or laissez-faire.

- Particular results are observed in the sports structures in which there are communication, passion and dedication relationships.

- To be able to cope with problematic situations in the contemporary sports system, sports managers must continuously and systematically improve their managerial training, including the techniques related to crisis management.

\section{Annex 1. Specialised questionnaire addressed to the managers of sports organizations}

In order to establish important aspects specific to sports management, please help me in identifying the ways and means of optimising their effectiveness and efficiency by kindly responding to the questionnaires prepared.

I inform you that the data are strictly for scientific study and are confidential.

Thank you!

1. Socio-demographic data of the manager who runs the sports organization

Age

Gender ... M ... F ...

Level of education ...

Last graduated school ...

2. For how long have you been working as a manager of a sports organization?
a) 0-1 years
b) 1-3 years
c) 4-6 years
d) 7-9 years
e) $<10$ years

3. To what extent do you consider that training and managerial skills are necessary to capitalise on the opportunities and success of sports organizations?

a) Not important 
b) Little important

c) According to

d) Important

e) Very important

4. How do you appreciate the importance of operational systems (sponsorships, procedures, systems and knowledge) on the results obtained?
a) Not important
b) Little important
c) According to
d) Important
e) Very important

5. How important are the following competencies in the activity of a sports manager?

\begin{tabular}{|l|l|l|l|l|l|}
\hline \multicolumn{1}{|c|}{ Competencies } & Unimportant & Less important & Suitable & Important & Very important \\
\hline $\begin{array}{l}\text { Motivation of staff } \\
\text { and athletes }\end{array}$ & & & & & \\
\hline Staff evaluation & & & & & \\
\hline Setting priorities & & & & & \\
\hline Setting objectives & & & & & \\
\hline Time management & & & & & \\
\hline Communication & & & & & \\
\hline Giving tasks & & & & & \\
\hline
\end{tabular}

6. How useful are the following managerial functions to the leaders of sports organizations?

\begin{tabular}{|l|l|l|l|l|}
\hline \multicolumn{1}{|c|}{ Functions of management } & Not useful & Suitable & Useful & Very useful \\
\hline Organization & & & & \\
\hline Coordination & & & & \\
\hline Planning & & & & \\
\hline Training & & & & \\
\hline Evaluation - Control & & & \\
\hline
\end{tabular}

7. Do you think that the current organizational structure of sports organizations is appropriate to their needs?
a) Inappropriate
b) A little adequate
c) I'm not sure
d) Suitable
e) Very appropriate

8. The performance of athletes is influenced by:

\begin{tabular}{|l|l|l|l|l|l|}
\hline \multicolumn{1}{|c|}{ Actions } & Very little & Little & Moderate & A lot & Excessively \\
\hline Evaluation of athletes & & & & & \\
\hline Training methods & & & & & \\
\hline Club's budget & & & & & \\
\hline Coach's experience and competence & & & & & \\
\hline Facilities & & & & & \\
\hline
\end{tabular}


9. How important do you consider the motivation of athletes to achieve the proposed performance?
a) Not important
b) Little important
c) Suitable
d) Important
e) Very important

10. How satisfied are you with the performance of athletes and collaborators?

\begin{tabular}{|l|l|l|}
\hline \multicolumn{1}{|c|}{ Appreciation } & \multicolumn{1}{|c|}{ Athletes } & Collaborators \\
\hline Dissatisfied & & \\
\hline Slightly satisfied & & \\
\hline Suitable & & \\
\hline Satisfied & & \\
\hline Very pleased & & \\
\hline
\end{tabular}

11. What are the ways to motivate your club's athletes? Respond with yes or no.

\begin{tabular}{|l|l|l|}
\hline \multicolumn{1}{|c|}{ Motivation } & \multicolumn{1}{c|}{ Yes } & No \\
\hline Remuneration from salaries and bonuses & & \\
\hline Diplomas and distinctions & & \\
\hline Verbal appreciations & & \\
\hline Penalties & & \\
\hline Others & & \\
\hline
\end{tabular}

12. How important do you think public relations are in the activity of your organization?
a) Not important
b) Little important
c) According to
d) Significant
e) Very important

13. Appreciate the length of your time dedicated to managerial activities in a working day.

\begin{tabular}{|l|c|}
\hline \multicolumn{1}{|c|}{ Activities } & Minutes allowed \\
\hline Planning, organization, coordination, evaluation, assistance & \\
\hline Audiences & \\
\hline Telephone calls & \\
\hline Meetings & \\
\hline Correspondence & \\
\hline Visits & \\
\hline Other activities & \\
\hline
\end{tabular}

14. How do you appreciate the financial characteristics achieved through the management strategies in relation to the needs of the organization you run?
a) Unsatisfactory
b) Satisfactory to a small extent
c) Neutral
d) Satisfactory
e) Very satisfactory 
15. How do you appreciate your interaction with local authorities to solve the problematic situations in which they have competence?
a) Unsatisfactory
b) Satisfactory to a small extent
c) Neutral
d) Satisfactory
e) Very satisfactory

16. Mention at most three sources of financing accessed by your club from the ones mentioned below:
a) Sponsorship
b) Contributions
c) Transfers
d) Advertising
e) Initiation of counter costs in a sports branch
f) Rental
g) Other sources

17. In the case of a deficit, how do you think the available work can be increased?
a) Supplementation of jobs
b) Productivity
c) Extra hours
d) Substitution of work with capital
e) Collaborations

18. How important do you think the professional training courses regularly followed by the staff are?
a) Not important
b) Little important
c) According to
d) Significant
e) Very important

19. What is the frequency of your athletes' participation in official international competitions?
a) Very rare
b) Rare
c) According to
d) Sometimes
e) Very often 
20. What is the number of athletes selected at the Olympic centres or national teams?

\begin{tabular}{|l|l|l|}
\hline \multicolumn{1}{|c|}{ Records } & Individual sports & Team sports \\
\hline $0-5$ & & \\
\hline $5-10$ & & \\
\hline $10-15$ & & \\
\hline$<15$ & & \\
\hline
\end{tabular}

\section{Annex 2. Multifactor Leadership Questionnaire}

Instructions: The present questionnaire highlights the managerial style. Analyse and select the option that suits you from the following statements. You will remain anonymous, and the data will be used only for the contribution of our research.

The following response scale will be used: 0 - Not at all, 1 - Very rare, 2 - Sometimes, 3 Quite often, 4 - Frequently or always.

\begin{tabular}{|c|c|c|c|c|c|c|}
\hline 1 & I help others unconditionally & 0 & 1 & 2 & 3 & 4 \\
\hline 2 & I double-check options before making a decision & 0 & 1 & 2 & 3 & 4 \\
\hline 3 & I give others the opportunity to find new solutions to older problems & 0 & 1 & 2 & 3 & 4 \\
\hline 4 & I have an expression for everyone & 0 & 1 & 2 & 3 & 4 \\
\hline 5 & I focus on errors that deviate from the standard & 0 & 1 & 2 & 3 & 4 \\
\hline 6 & I am pleased when the majority complies with the agreed decisions & 0 & 1 & 2 & 3 & 4 \\
\hline 7 & When asked, I respond promptly and without hesitation & 0 & 1 & 2 & 3 & 4 \\
\hline 8 & Relationships with others are based on trust & 0 & 1 & 2 & 3 & 4 \\
\hline 9 & I am a visionary and come up with new suggestions for what to do & 0 & 1 & 2 & 3 & 4 \\
\hline 10 & I analyse the responsibilities of each for the efficiency of achieving the goals & 0 & 1 & 2 & 3 & 4 \\
\hline 11 & Before I make the decisions I expect failure & 0 & 1 & 2 & 3 & 4 \\
\hline 12 & When others reach their goals, they recognize their merits and reward them & 0 & 1 & 2 & 3 & 4 \\
\hline 13 & Others feel a sense of pride when they are associated with me & 0 & 1 & 2 & 3 & 4 \\
\hline 14 & I don't intervene as long as things are going well & 0 & 1 & 2 & 3 & 4 \\
\hline 15 & I offer feedback on the activity of others & 0 & 1 & 2 & 3 & 4 \\
\hline 16 & I encourage, support and guide those who want to develop professionally & 0 & 1 & 2 & 3 & 4 \\
\hline 17 & I pay attention to the rewards and bonuses of those who reach their goals & 0 & 1 & 2 & 3 & 4 \\
\hline 18 & I do not intervene in changing the working methods of others & 0 & 1 & 2 & 3 & 4 \\
\hline 19 & I do not demand more from others than the strictly necessary & 0 & 1 & 2 & 3 & 4 \\
\hline 20 & Only take action when problems become obvious & 0 & 1 & 2 & 3 & 4 \\
\hline 21 & I prefer to develop the association before personal interests & 0 & 1 & 2 & 3 & 4 \\
\hline 22 & Through the prism of my actions I impose the respect of others & 0 & 1 & 2 & 3 & 4 \\
\hline 23 & I consider it a priority to complete my actions during the scheduled time & 0 & 1 & 2 & 3 & 4 \\
\hline 24 & I am careful and I try to solve the problems and dissatisfaction of those around & 0 & 1 & 2 & 3 & 4 \\
\hline 25 & When making my decisions, I consider the ethical and moral consequences & 0 & 1 & 2 & 3 & 4 \\
\hline 26 & I inform others about the standards they need to know to perform their tasks & 0 & 1 & 2 & 3 & 4 \\
\hline 27 & I pay attention to those who seem not to integrate & 0 & 1 & 2 & 3 & 4 \\
\hline 28 & I help others give importance to the work I do & 0 & 1 & 2 & 3 & 4 \\
\hline 29 & I urge those around you to take a closer look at the issues & 0 & 1 & 2 & 3 & 4 \\
\hline 30 & I am convinced that the objectives will be met & 0 & 1 & 2 & 3 & 4 \\
\hline 31 & My leadership methods thank those I work with & 0 & 1 & 2 & 3 & 4 \\
\hline 32 & $\begin{array}{l}\text { I appreciate that each individual has different needs, aspirations and aptitudes than the } \\
\text { others }\end{array}$ & 0 & 1 & 2 & 3 & 4 \\
\hline 33 & I have a representation about the persevering future & 0 & 1 & 2 & 3 & 4 \\
\hline 34 & I insist on the collective awareness of the objectives that must be met & 0 & 1 & 2 & 3 & 4 \\
\hline 35 & I systematically record all errors and errors & 0 & 1 & 2 & 3 & 4 \\
\hline 36 & I intensify aspirations to make sustained efforts & 0 & 1 & 2 & 3 & 4 \\
\hline 37 & I speak with exaltation about the action to be taken & 0 & 1 & 2 & 3 & 4 \\
\hline 38 & I confess my beliefs and values to those around me & 0 & 1 & 2 & 3 & 4 \\
\hline
\end{tabular}




\begin{tabular}{|c|c|c|c|c|c|c|}
\hline 39 & I am efficient in resolving service tasks & 0 & 1 & 2 & 3 & 4 \\
\hline 40 & I amplify the desire for success of others & 0 & 1 & 2 & 3 & 4 \\
\hline 41 & I am the leader of a collective with efficiency & 0 & 1 & 2 & 3 & 4 \\
\hline 42 & My high standards lead to high quality work & 0 & 1 & 2 & 3 & 4 \\
\hline 43 & I correct mistakes to reach goals & 0 & 1 & 2 & 3 & 4 \\
\hline 44 & I am proud to represent the interests of the organization & 0 & 1 & 2 & 3 & 4 \\
\hline
\end{tabular}

\section{References}

Antonakis, J., Avolio, B. J., \& Sivasubramaniam, N. (2003). Context and leadership: An examination of the nine-factor full-range leadership theory using the Multifactor Leadership Questionnaire. The Leadership Quarterly, 14(3), 261-295.

https://doi.org/10.1016/S1048-9843(03)00030-4

Asrar-ul-Haq, M., \& Anwar, S. (2018). The many faces of leadership: Proposing research agenda through a review of literature. Future Business Journal, 4(2), 179-188. https://doi.org/10.1016/j.fbj.2018.06.002

Colibaba-Evuleț, D., \& Bota, I. (1998). Jocuri sportive: Teorie și metodică [Sports games: Theory and methodology]. București: Aldin.

Endres, G. J., \& Kleiner, B. H. (1990). How to measure management training and development effectiveness. Journal of European Industrial Training, 14(9). https://doi.org/10.1108/03090599010137102

Gavrilă, T., \& Lefter, V. (2002). Managementul general al firmei [Overall management of the company]. București: Editura Economică.

Henricks, M. D., Young, M., \& Kehoe, E. J. (2020). Attitudes toward change and transformational leadership: A longitudinal study. Journal of Change Management, 20(3). https://doi.org/10.1080/14697017.2020.1758529

Iliescu, D., Mocanu, R., \& Beldean, F. (2008). MLQ (Chestionarul Multifactorial de Leadership). Date preliminare pentru România [MLQ (Multifactorial Leadership Questionnaire). Preliminary data for Romania]. Psihologia Resurselor Umane, 6(1), 4763. https://doi.org/10.24837/pru.v6i1.346

Ion, I. (2011). Measuring human capital - A scientific utopia? International Journal of Pluralism and Economics Education, 2(2), 162-169. https://doi.org/10.1504/IJPEE.2011.041696

Lussier, R. N., \& Kimball, D. C. (2009). Applied sport management skills. Champaign, IL: Human Kinetics.

Mihăilescu, N. (2006). Management. Marketing. Legislație în sport [Management. Marketing. Legislation in sport]. Pitești: Editura Universităţii din Pitești.

Salaga, S., \& Juravich, M. (2020). National Football League head coach race, performance, retention, and dismissal. Sport Management Review. https://doi.org/10.1016/j.smr.2019.12.005

Smith, N. L., \& Green, B. C. (2020). Examining the factors influencing organizational creativity in professional sport organizations. Sport Management Review. https://doi.org/10.1016/j.smr.2020.02.003

Strategic planning. (2014). Scandinavian Journal of Public Health. https://doi.org/10.1177\%2F1403494813515117

Zhang, J. J., Kim, E., Mastromartino, B., Qian, T., Y., \& Nauright, J. (2018). The sport industry in growing economies: Critical issues and challenges. International Journal of Sports Marketing and Sponsorship, 19(2), 110-126.

https://doi.org/10.1108/IJSMS-03-2018-0023 